\title{
Digito-palmar Dermatoglyphics as Biomarkers of Dental and Medical Disorders
}

\author{
Heshmat S W Haroun* \\ Professor of Anatomy and Embryology, Anatomy Department, Cairo University, Egypt \\ *Corresponding author: Professor of Anatomy and Embryology, Anatomy Department, Kasr Al Ainy Faculty of Medicine, Cairo \\ University, Egypt
}

\begin{abstract}
Digito-palmar dermatoglyphics is the study of the configurations and pattern-frequencies of the epidermal ridges on the palms and finger pads. They are ectodermal in origin, develop in early embryonic life, and remain unaltered throughout the rest of life. Fingerprints and handprints are widely used in criminology. Recently, digito-palmar dermatoglyphics have been utilized as biomarkers for detection of some dental, malignant, chromosomal, skin, ocular, and medical disorders.
\end{abstract}

Keywords: Dermatoglyphics; Biomarkers; Dental Disorders; Malignancies; Chromosomal Abnormalities; Skin and Eye Diseases; Diabetes Mellitus; Hypertension

Abbreviations: AFRC: Absolute Finger Ridge Count; ALL: Acute Lymphoblastic Leukemia; ANM: Acanthosis Nigricans Maligna; ECC: Early Childhood Caries; FCP: Florid Cutaneous Papillomatosis; OSCC: Oral Squamous Cell Carcinoma; OSMF: Oral Submucous Fibrosis; POAG: Primary Open Angle Glaucoma; THCS: Tel Hashomer Camptodactyly Syndrome; TP: Tripe Palm; TRFC: Total Finger Ridge Count

\section{Introduction}

Dermatoglyphics is the scientific investigation of the morphology and pattern-frequency of the skin ridges on the palms, soles and digital pads. They develop from the ectoderm germ layer in early embryonic period and remain stable throughout life. In a previous article, we reviewed the ethnicity-, age-, sex-, and laterality-related variations of digito-palmar dermatoglyphics; their role as predictors of brain disorders was discussed [1]. Here, a review is made concerning the utilization of alterations in the digito-palmar dermatoglyphics as biomarkers for the diagnosis of dental and medical disorders.

\section{Dermatoglyphics In Dental Disorders}

\section{a) In Malocclusion}

Craniofacial elements and epidermal ridges are ectodermal structures developed early in embryonic period. Genetic and environmental factors causing malocclusion are also thought to induce morphological alterations in fingerprint patterns; suggesting the dermatoglyphics as an effective tool for prediction of malocclusion [2]. Significantly increased twinned loops and absent radial loops on fingertips were observed in individuals with malocclusions when compared to those with normal occlusions; handprints revealed non-significant alterations [3].

\section{b) In Dental Caries}

The epidermis of finger ridges and the dental enamel are ectodermal in origin developing in the same embryonic period, therefore dermatoglyphic patterns were used as a genetic marker for dental caries. Susceptibility to dental caries was observed to be linked to an increased frequency of whorl pattern and decreased incidence of loop pattern.[4] In an investigation on preschool children of Lucknow, India dental caries susceptibility was associated with significantly increased frequency of whorl pattern and significantly decreased frequency of arch pattern, of fingerprints [5]. In Bengalese children with dental caries, there were significantly increased total finger ridge count (TRFC) and absolute finger ridge count (AFRC) in addition to significantly changed frequency of palmar patterns and number of palmar triradii [6]. It has been generally stated that the incidence of whorls in the right index fingertip predicts significantly lower risk of early childhood caries (ECC) in both sexes whereas the incidence of whorls in the right ring fingertip predicts significantly lower risk of ECC in female children [7]. 


\section{c) In Edentulous Arches}

Digito-palmar dermatoglyphics, in edentulous individuals, were used as an effective tool for predicting the shape of the original dental arch. A significantly increased frequency of loops and a large "atd" angle predicted original square dental arches, a significantly increased frequency of whorls and a small "atd" angle predicted original tapering dental arches, and a significantly increased frequency of loops alone predicted original ovoid dental arches [8].

\section{Dermatoglyphics In Malignancies}

Tumors, in general, are associated with alterations in the digitopalmar dermatoglyphics in the form of decreased number of ridges between the triradii of both palms and between the triradii of $\mathrm{c}-\mathrm{d}$. Endocrine tumors, in particular, are associated with increased number of arches and decreased number of whorls in addition to different pattern distribution in the I3 and I4 interdigital spaces. Different pattern distribution in I1 and I2 interdigital spaces could point out to the presence of a pituitary tumor [9]. It has been also decided that palmar dermatoglyphics could be of help in discriminating individuals at high risk of oral submucous fibrosis (OSMF) and oral squamous cell carcinoma (OSCC).[10] In both OSCC and OSMF, there were increased frequency of arch and ulnar loop patterns and decreased frequency of simple whorl pattern on fingertips, in addition to decreased frequency of palmar accessory triradii on both palms (in OSCC) and decreased value of "atd" angle and decreased frequency of palmar accessory triradii on right palm (in OSMF) [11]. Palmar "atd" angle was utilized in screening women at high risk of breast cancer. Females with breast carcinoma, when compared with phenotypic healthy controls, showed significant quantitative "atd" angle differences between right and left palms [12].

In another study, carcinoma of female breast was observed to be associated with other digito-palmar dermatoglyphic changes like significantly increased frequency of arch pattern and decreased frequency of radial loops in both thumbs, left index finger and left middle finger. Added to these changes, there were lower values of TFRC and AFRC in conjunction with breast carcinoma [13]. Gastric adenocarcinoma, in a 76-year-old male, was diagnosed to be associated with three types of dermatoses: tripe palms (TP), acanthosis nigricans maligna (ANM), and florid cutaneous papillomatosis (FCP). TP was a yellowish diffuse palmar hyperkeratosis with enhanced dermatoglyphics of both palms, ANM was an extensive hyperkeratotic and hyperpigmented mucocutaneous eruption with exaggerated skin markings and verrucous excrescences and FCP included rapid appearance of multiple wart-like verrucous lesions [14]. Children with acute lymphoblastic leukemia (ALL) exhibited increased mean values of "ab" ridge count and "atd" angle when compared to the controls [15]. Any of the two unusual transverse palmar flexion creases: simian or Sydney-creases was detected, often on both palms, in more than $50 \%$ of Caucasian children suffering from malignant neoplasms. In children with ALL, the Sydney-crease was the most commonly encountered abnormal palmar flexion crease [16].

\section{Dermatoglyphics In Chromosomal Aberrations}

Palmar dermatoglyphics is known to be a valuable diagnostic tool in genetic disorders. In most palms, when the fingers are slightly flexed, two transverse flexion creases could be seen. In a minority of palms, a single transverse flexion crease may be found in one hand (the simian crease) or the usual two creases are present with one of them traversing across the palm to its ulnar margin (the Sydneycrease). In a group of "at risk" newborns, increased frequency of abnormal palmar creases (simian and Sydney) was determined. A parents' index score, using palmar dermatoglyphics (simian crease and palmar hypothenar pattern), was established as a predictive tool to discriminate parents of Down's syndrome (trisomy 21) children from healthy controls [17-21]. In 22 out of 24 aborted human fetuses, palmar dermatoglyphic alterations correlated well with the amniocentesis- diagnosed chromosomal aberrations: trisomy 21 , trisomy 18, trisomy 13 , structural autosomal aberrations and sex-chromosome aberration [22]. Unusual changes of the palmar creases in preschool children with psychomotor retardation (not of Down's syndrome origin) were evaluated to be as twice more frequent as their parents and school children [23].

Exposure of the embryo to deleterious environmental factors could lead to diseases that appear later in life and to marked palmar dermatoglyphic dissimilarities in the twins particularly in the III and IV interdigital and hypothenar areas [24]. In both monozygotic and dizygotic twins, the impact of genetic factors on the pattern distribution of palmar dermatoglyphics was decided to be the highest in the III interdigital area and the lowest in the IV interdigital region [25]. In two cases of Marfan's syndrome, simian crease, extra-digital transverse crease, increased "atd" angle, and high position of the axial triradus were reported [26]. In cytogenetically confirmed $46, \mathrm{XY}$ females, the overall fingertip patterns showed increased frequency of ulnar loops and decreased frequency of whorls when compared to control males, their right thumbs revealed decreased frequency of whorls and increased frequency of ulnar loops in addition to decreased TFRC, AFRC, and $\mathrm{a}-\mathrm{b}$ ridge count when compared to controls of both sexes. Non-significant differences in the "atd" angle, interdigital and hypothenar patterns, and simian and Sydney- creases were assessed between the tested females and their control of both sexes [27]. Tel Hashomer camptodactyly syndrome (THCS), as a rare autosomal recessive disease, is manifested with camptodactyly, clubbed feet, thenar and hypothenar hypoplasia, abnormal palmar creases and dermatoglyphic ridges, spina bifida and mitral valve prolapse [28]. Moreover, other dermatoglyphic changes were observed in the rare cases of THCS like increased frequency of whorl and arch patterns with tendency toward increased TFRC [29].

\section{Dermatoglyphics In Skin Disorders}

In vitiligo males, when compared with the controls, there were increased pattern frequency in right hypothenar and thenar areas and in both II interdigital areas, together with decreased pattern frequency in the right III and IV interdigital areas. Vitiligo females revealed increased pattern frequency in right hypothenar and 
interdigital area I and decreased pattern frequency in right II and left III interdigital areas. Some of these dermatoglyphic variations were statistically significant [30]. In another study on vitiligo patients, when compared with the controls, significantly increased frequency of whorls in males and of arches in females were evaluated. In addition, simian and Sydney- creases, highly significant reduction in TFRC and a-b ridge count, and non- significant alterations in the values of "atd" angle were observed in both sexes [31]. In severe hand dermatitis (eczema), there was a failure of fingerprint verification in $27 \%$ of patients compared to $2 \%$ of controls. Hand dermatitis, in these patients, was manifested by fingerprint dystrophy and significantly increased number of abnormally long and broad white streaks [32]. Patients with multibacillary leprosy, when compared to controls, showed a significantly increased pattern frequency in the left thenar/1st interdigital area. A highly significant frequency of simian crease was also assessed in palms of both multibacillary and paucibacillary types of leprosy, with nonsignificant alterations in the values of "atd" angle [33].

\section{Dermatoglyphics In Ocular Disorders}

Digito-palmar dermatoglyphic changes were utilized to discriminate between patients with primary open angle glaucoma (POAG) and their immediate (first-degree) relatives from phenotypically healthy individuals. POAG results from abnormal outflow of aqueous humour through the trabecular meshwork of the vascular coat of the eye which develops at the same time as dermatoglyphics [34,35].

\section{Dermatoglyphics In Congenital Disorders}

In congenital heart disease (CHD) like Fallot's tetralogy, patent ductus arteriosus, pulmonic stenosis, and atrial and ventricular septal defects, when compared to controls, there were altered digito-palmar dermatoglyphics like incidence of accessory triradii, missing of " $c$ " triradius, increased TFRC, variations in palmar ridge counts (a-b, b-c, c-d, a-d and t-d, and significantly decreased t-d ridge count [36,37]. In congenital hand anomalies, particularly ectrodactyly and syndactyly, when compared to the controls, there were discriminative changes in the number of digital triradii, the position of an axial triradius, the pattern intensity, and the incidence of hypothenar patterns [38]. Fluctuating asymmetry (a significantly increased variation of the mean values) and increased incidence of ridge dissociation of digito-palmar dermatoglyphics were observed in patients with congenital vertebral malformations, suggesting an insult occurring during embryogenesis that led to these anomalies [39].

\section{Dermatoglyphics In Diabetes Mellitus and Hypertension}

In type 1 diabetes mellitus, predictive changes in digito-palmar dermatoglyphics were assessed in the form of decreased third finger ridge count and a-b ridge count, higher transverse position of the main palmar lines, increased frequency of palmar axial $\mathrm{t}^{\prime}$ and $\mathrm{t}$ " triradii, and decreased pattern frequency in the fourth interdigital and thenar areas [40]. In hypertensive patients of both sexes, when compared to healthy controls, significant palmar dermatoglyphic alterations were observed like increased TFRC, decreased frequency of axial triradius $t^{\prime}$ in female right palms and axial triradii $t^{\prime}$ and $t^{\prime \prime}$ in male right palms, and decreased values of "atd" angle [41]. In black Malawian patients, the TFRC was used as a predictor of hypertension and the a-b ridge count as a predictor of concomitant diabetes mellitus and hypertension, in both sexes. Digito-palmar dermatoglyphics displayed absence of whorls in hypertensives of both sexes and in men with concomitant diabetes mellitus and hypertension. Also, there were significantly increased frequency of ulnar loops in hypertensive women and significantly decreased frequency of whorls in women with both diabetes and hypertension more than in women with hypertension alone [42]. In a different investigation, it was determined that the mean value of "atd" angle to be higher and the whorls to be significantly more frequent in hypertensives than in normotensives [43].

\section{Conclusion}

Epidermal ridges are developed, from ectoderm, in early embryonic period. Any deviation of their morphological patterns and frequencies may point out to genetic or environmental factors that also negatively impact other body systems. The usage of digito-palmar dermatoglyphics as biomarkers of predisposition to several dental and medical disorders could help in early detection and management of these diseases. It is emphasized that dermatoglyphics should not be used alone as a diagnostic tool but in conjunction with the physical examination of the patients.

\section{References}

1. Haroun HSW (2019) Digito-palmar dermatoglyphics: variations and prediction of brain disorders. MOJ Anat \& Physiol 6(3): 103-106.

2. Tikare S, Rajesh G, Prasad KW, Thippeswamy V, Javali SB (2010) Dermatoglyphics-a marker for malocclusion? Int Dent J 60(4): 300-304.

3. Reddy BR, Sankar SG, E T R, Govulla S (2013) A comparative study of dermatoglyphics in individuals with normal occlusions and malocclusions. J Clin Diagn Res 7(12): 3060-3065.

4. Abhilash PR, Divyashree R, Patil SG, Gupta M, Chandrasekar T, et al. (2012) Dermatoglyphics in patients with dental caries: a study on 1250 individuals. J Contemp Dent Pract 13(3): 266-274.

5. Singh E, Saha S, Jagannath GV, Singh S, Saha S, et al. (2016) Association of dermatoglyphic peculiarities with dental caries in preschool children of Lucknow, India. Int J Clin Pediatr Dent 9(1): 39-44.

6. Sengupta AB, Bazmi BA, Sarkar S, Kar S, Ghosh C, et al. (2013) A cross sectional study of dermatoglyphics and dental caries in Bengalee children. J Indian Soc Pedod Prev Dent 31(4): 245-248.

7. Navit S, Chadha D, Khan SA, Singh RK, Johri N, et al. (2015) The mystery of handprints: assessment and correlation of dermatoglyphics with early childhood caries a case-control study. J Clin Diagn Res 9(10): 44-48.

8. Sachdeva S, Tripathi A, Kapoor P (2014) Dermatoglyphic assessment in subjects with different dental arch forms: an appraisal. J Indian Prosthodont Soc 14(3): 281-288.

9. Gradiser M, Matovinovic Osvatic M, Dilber D, Bilic Curcic I (2016) Assessment of environmental and hereditary influence on development of pituitary tumors using dermatoglyphic traits and their potential as screening markers. Int J Environ Res Public Health 13(3): 330.

10. Vijayaraghavan A, Aswath N (2015) Qualitative and quantitative analysis of palmar dermatoglyphics among smokeless tobacco users. Indian J Dent Res 26(5): 483-487.

11. Gupta A, Karjodkar FR (2013) Role of dermatoglyphics as an indicator of precancerous and cancerous lesions of the oral cavity. Contemp Clin Dent 4(4): 448-453. 
12. Metovic A, Musanovic J, Alicelebic S, Pepic E, Sljuka S, et al. (2018) Predictive analysis of palmar dermatoglyphics in patients with breast cancer for small Bosnian-Herzegovinian population. Med Arch 72(5): 357-361.

13. Raizada A, Johri V, Ramnath T, Chowdhary D, Garg R (2013) A crosssectional study on the palmar dermatoglyphics in relation to carcinoma breast patients. J Clin Diagn Res 7(4): 609-612.

14. Yang YH, Zhang RZ, Kang DH, Zhu WY (2013) Three paraneoplastic signs in the same patient with gastric adenocarcinoma. Dermatol Online J 19(7): 18966

15. Bukelo MJ, Kanchan T, Rau AT, Unnikrishnan B, Bukelo MF, et al. (2011) Palmar dermatoglyphics in children with acute lymphoblastic leukemiaa preliminary investigation. J Forensic Leg Med 18(3): 115-118.

16. Oorthuys AM, de Vaan GA, Behrendt H, Geerts SJ (1979) Palmar flexion creases in childhood neoplasia. Cancer 43(2): 749-759.

17. Dar H, Schmidt R, Nitowsky HM (1977) Palmar crease variants and their clinical significance: a study of newborns at risk. Pediatr Res 11(2): 103108.

18. Cummins H, Talley C, Platou RV (1950) Palmar dermatoglyphics in mongolism. Pediatrics 5(2): 241-248.

19. Zajaczkowska K (1969) Palmar dermatoglyphics in patients with Down's syndrome and in their parents. Pol Med J 8(6): 1477-82.

20. Plato CC, Cereghino JJ, Steinberg FS (1973) Palmar dermatoglyphics of Down's syndrome: revisited. Pediatr Res 7(3): 111-118.

21. Ayme S, Mattei MG, Mattei JF, Aurran Y, Giraud F (1979) Dermatoglyphics in parents of children with trisomy 21 . Evaluation of their interest in genetic counselling. Clin Genet 15(1): 78-84.

22. Katznelson MB, Goldman B (1982) Fetal dermatoglyphics. Clin Genet 21(4): 237-242.

23. Dar H, Bolchinsky D, Jaffe M, Winter ST (1978) Routine analysis of dermatoglyphics and palmar creases in children with developmental disorders. Dev Med Child Neurol 20(6): 735-737.

24. Temaj G, Skarić Jurić T, Tomas Z, Behluli I, Smolej Narančić N, et al. (2012) Qualitative dermatoglyphic traits in monozygotic and dizygotic twins of Albanian population in Kosovo. Homo 63(6): 459-467.

25. Jacques SM, Salzano FM, Penña HF (1977) Palmar dermatoglyphic patterns in twins. Hum Hered 27(6): 437-443.

26. Permalatha S, Kannaki K, Sukumar P (1985) Palmar Dermatoglyphics in Marfan's Syndrome. Indian J Dermatol Venereol Leprol 51(2): 87-89.

27. Bosco JI, Rajangam S, Shankar J, Thomas IM (2001) Dermatoglyphics in 46, XY females. J Indian Med Assoc 99(8): 418-420.

28. Shah K, Sreekanth R, Thomas B, Danda S (2013) Tel Hashomer camptodactyly syndrome: a case report. West Indian Med J 62(1): 81-83.
29. Wijerathne BT, Meier RJ, Agampodi SB (2016) The status of dermatoglyphics as a biomarker of Tel Hashomer camptodactyly syndrome: a review of the literature. J Med Case Rep 10(1): 258.

30. Bhakta A, Mistri S, Mondal GC, Bandyopadhyay M, Bhattacharaya et al. (2011) True palmar pattern in vitiligo-a case control study. Nepal Med Coll J 13(4): 241-246.

31. Iqbal S, Premalatha S, Zahra A (1985) Dermatoglyphics in vitiligo. Int J Dermatol 24(8): 510-513.

32. Lee CK, Chang CC, Johar A, Puwira O, Roshidah B (2013) Fingerprint changes and verification failure among patients with hand dermatitis. JAMA Dermatol 149(3): 295-299.

33. Gupta CM, Tutakne MA (1986) An evaluation of palmar flexion creases and dermatoglyphics in leprosy. Indian J Lepr 58(2): 263-275.

34. Novak Laus K, Milicić J, Tedeschi Reiner E, Iveković R, Mijić V, et al. (2005) Analysis of the quantitative dermatoglyphic traits of the digito-palmar complex in patients with primary open angle glaucoma. Coll Antropol 29(2): 637-642.

35. Novak Laus K, Milicić J, Tedeschi Reiner E, Iveković R, Korsić J, et al. (2006) Analysis of the qualitative dermatoglyphics of the digito-palmar complex in patients with primary open angle glaucoma. Coll Antropol 30(1): 163-170.

36. David TJ (1981) Dermatoglyphs in congenital heart disease. J Med Genet 18(5): 344-349.

37. Ahuja YR, Annapurna V, Reddy YR, Reddy GD, Rao VS, et al. (1982) Dermatoglyphic studies in congenital heart disease in India. Acta Anthropogenet 6(3): 141-150.

38. Watanabe K, Nakamura R, Miura T (1994) Palmar dermatoglyphics in congenital hand anomalies. J Hand Surg Am 19(6): 961-967.

39. Goldberg CJ, Fogarty EE, Moore DP, Dowling FE (1976) Fluctuating asymmetry and vertebral malformation. A study of palmar dermatoglyphics in congenital spinal deformities. Spine (Phila $\mathrm{Pa}$ ) 22(7): 775-779.

40. Ziegler AG, Mathies R, Ziegelmayer G, Baumgartl HJ, Rodewald A, et al. (1993) Dermatoglyphics in type 1 diabetes mellitus. Diabet Med 10(8): 720-724.

41. Pursnani ML, Elhence GP, Tibrewala L (1989) Palmar, dermatoglyphics in essential hypertension. Indian Heart J 41(2): 119-122.

42. Igbigbi PS, Ng'ambi TM (2004) Palmar and digital dermatoglyphic features of hypertensive and diabetic Malawian patients. Malawi Med J 16(1): 1-5.

43. Chakravathy P G, Shirali A, Chowta KN, Ramapuram JT, Madi D, et al (2018) A "Handy" tool for hypertension prediction: Dermatoglyphics. Indian Heart J 70(3): S116-S119.
To Submit Your Article Click Here: Submit Article

DOI: $10.32474 /$ SJ0.2019.02.000148

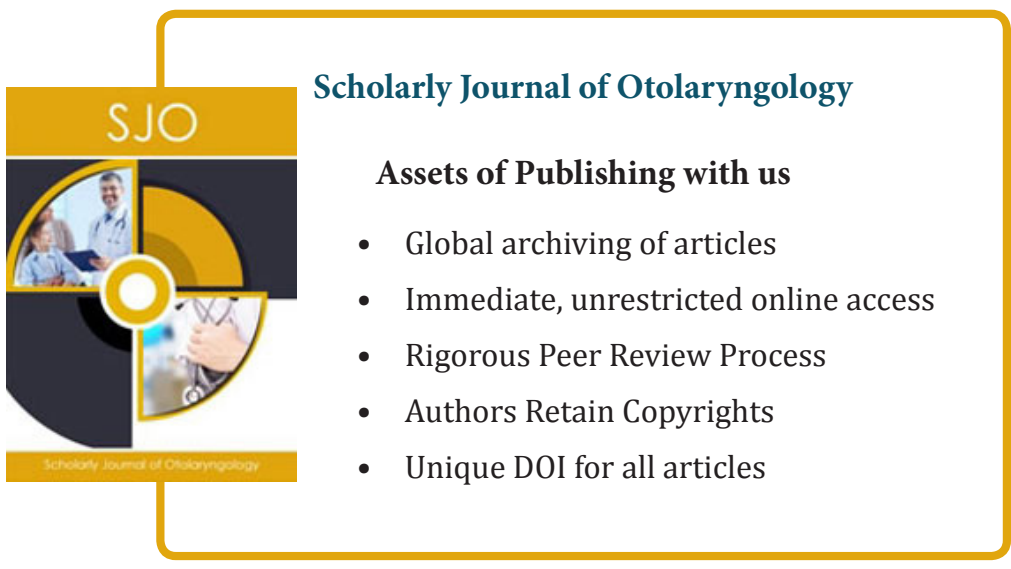

